\title{
CORRESPONDENCE
}

Correspondents are asked to be brief

Specialist Training in Medicine

SIR,-I would be most grateful to use your correspondence columns to make a report on the progress of the approval of training posts for higher specialist training.

We now have had a considerable number of applications for visits to training posts Some visits have already been made and it is hoped to make an intensive effort in the first half of 1974. In an earlier announcement (23 June, 1973, p. 724) it was made clear that posts suitable for general professional training would not be visited by the Joint Committee on Higher Medical Training. These posts are being dealt with in Scotland by the Scottish Council for Postgraduate Medical Education and in England, Wales, and Northern Ireland by the Roya College of Physicians of London. We realize that there is still some misunderstanding about the difference between the two kinds of

\section{Screening for Cervical Cancer}

SIR,-I read with considerable anticipation and interest your leading article on the "Uncertainties of Cervical Cytology" (1 December, p. 501), but came to the conclusion that it was out of date.

Most gynaecologists and cytologists now agree that screening for in situ cervical carcinoma can lower the rate of invasive disease and eventually the mortality. ${ }^{1}$ Professor E. G. Knox in his paper "The Epidemiologist"2 described his computer simulations and found that screening programmes are worthwhile. Surely the fall in the standardized mortality rates from cancer of the cervix at ages 45-64 years since 1965, reported recently from British Columbia, is what would be expected if screening is effective?

The fall in incidence of this disease reported from Aberdeen ${ }^{4}$ continues and there has been a fall in mortality rate,,$^{5}$ which is three times greater than the average fall reported in England and Wales. This fall is mainly attributed to the removal of the cases of micro-invasive preclinical cancers rather than to the removal of carcinoma-in-situ which, because of its slow progression, will affect the death rates only later. There is certainly no "increasing tendency for total hysterectomy to replace cone-biopsies as therapy" in this region.

Well-organized screening which covers all social groups on a systematic basis and does not rely only on the women asking for the test is difficult to organize, but it can be done $^{6}$; the fact that the ensuing fall in incidence and mortality follows so naturally strongly suggests that its systematic use is the main causal factor.-I am, etc.,

J. ElizABETH MACGREgor Departments of Obstetrics and Gynaecology and

University of Aberdeen post. Recognition of posts for higher medical training will usually be made at senior registrar level. The numbers of these posts are related by the Departments of Health to the anticipated number of consultant vacancies, but a small number of registrar posts may be considered for recognition, provided that the training programme available meets the necessary requirements for the specialty as described in the Joint Committee's first report ${ }^{1}$ published in October 1972.-I am, etc.,

Cyril A. Clarke Chairman, Executive Committee,
Joint Committee on Higher Medical Training

Royal College of Physicians,
London N.W.1

1 Joint Committee on Higher Medical Training First Report. London, J.C.H.M.T. at the Roya College of Physicians, 1972. test and had M.I.C.s with long trailing endpoints as first described by Professor May and Mrs. Davies (12 August 1972, p. 376). The remaining strains were sensitive.-We are, etc.,

B. Cornere

R. MENZIES

Microbiology Department,

Green Lane Hospital,

1 Ericsson, H. M., and Shernis, J. C., Acta Pathologica et Microbiologica Scandinavica Section, $B, 1971$, Supple. No 217. p. 67

\section{Chemotherapy of Disseminated} Malignant Tumours

SIR,-Price and Goldie ${ }^{1}$ reported encouraging results in the treatment of various disseminated solid malignant tumours with multiple antitumour drugs. Complete or partial tumour regression was observed in 20 of their 40 patients, including three out of five with lung carcinoma.

We have now treated 17 patients with bronchial carcinoma in the Dundee Chest Service with schedule I of this regimen, using cyclophosphamide, fluorouracil, actinomycin $\mathrm{D}$, vincristine, methotrexate and cytosine arabinoside. The diagnosis was confirmed histologically in 14 patients. In the remaining three the clinical and $x$-ray findings and progress were in keeping with disseminated malignant disease. The histology of the tumours was as follows: oat cell, 5; poorly differentiated or anaplastic, 5; adenocarcinoma, 2; and squamous cell, 2 . In all but one of these patients there was evidence of dissemination of tumour. Four patients had had previous intravenous cyclophosphamide to a total of $4 \mathrm{~g}$. in each case. One had had additional oral cyclophosphamide for three months. Six patients had had previous radical but conventional radiotherapy. The number of treatments with the multiple cytotoxic regimen varied in individual cases from one to five, average two. In one patient mustine was substituted for cyclophosphamide but this was the only deviation from the prescribed regimen.

At the time of writing there are only three survivors, who started treatment four, five, and six months ago respectively. In the remaining 14 cases the average time from first treatment to death was $2 \frac{1}{2}$ months. In only one patient was there good evidence of clinical improvement (reduction in size of skin nodules). Ignoring fluctuating changes in chest radiographs there has been no evidence of radiological improvement. In keeping with the original report, the regimen has been well tolerated, the only side effects noted by our patients being significant alopecia in two cases (both in women) and vomiting in only one. Peripheral blood examination including leucocyte and platelet counts at two weeks after treatment commonly showed some leucopenia, but no serious blood dyscrasia was recorded.

fynd three types-the one already descril , and three strains (isolated than once) which were resistant to the disc 
In conclusion, in 17 patients with advanced bronchial carcinoma we have failed to confirm the optimistic results described by Price and Goldie in their preliminary report.-I am, etc.,

D. A. CoOK

Chest Clinic,

Dundee

1 Price, L. A., and Goldie, J. H., British Medical

fournal, 1971, 4, 336.

\section{Chemotherapy of Candidiasis}

SIR,-The paper on "Relevance of Antigenicity of Candida albicans Growth Phases to Diagnosis of Systemic Candidiasis," by Mr. E. G. V. Evans and others (13 October, p. 86) is most timely indeed, not only because of the increasing frequency of iatrogenic systemic candidiasis, as stated in the paper, but even more so since several promising antifungal agents have become available.

We have had the opportunity to use an injectable solution of miconazole, one such agent, which was made available to us for investigational use. Miconazole, 1-[2, 4dichloro- $\beta-(2,4$-dichlorobenzyloxy) phenethyl] imidazole, is a synthetic chemotheropeutic agent which is active against most pathogenic fungi, yeasts, and Grampositive bacteria. ${ }^{1}$ Miconazole has proved its therapeutic usefulness in dermatomycosis ${ }^{2}$ and vaginal candidiasis. ${ }^{3}$

We have used miconazole in 14 patients with systemic candidiasis proved by positive bronchial sputum, urine, or blood culture. Treatment was successful in all at the dose of 200-400 mg thrice daily for 5-30 days given intravenously or occasionally, as indicated by the primary site of the infection, also by such routes as direct instillation into the trachea, bladder, or renal pelvis. Treatment must be continued until the relevant cultures have become completely negative. The most striking advantage of miconazole has been its excellent local tolerance and the absence of renal, liver, or blood toxicity.

We also treated seven cancer patients with a persistent fever of unknown origin which was resistant to broad-spectrum antibiotics, on the assumption that the fever could have been due to candida infection though blood cultures were negative. Necropsy on such patients may reveal nidi of candida infection which could not be demonstrated during life. ${ }^{4}$ Miconazole given intravenously at a dose of $600 \mathrm{mg}$ per day made five of the seven patients subfebrile within three days, but even prolonged treatment did not change the febrile state of the other two patients.

Clearly for this category of patients accurate and fast diagnosis of candidiasis would be most desirable since effective therapy could then be started immediately. -We are, etc.,

Strahlenklinik Prof. Janker,

W. SCHEEF

Bonn, Germany

J. SYMOENS

Janssen Pharmaceutica,

Beerse

K. VAN CAMP

University of Antwerp U.I.A.

R. DANEELS

St. Jans Hospitaal,

C. De Leeuw-Delvigne

Algemeen Ziekenhuis Middelheim,

Antwerp, Belgium
1 Van Cutsem, J. M., and Thienpont, D., Chemotherapy, 1972, 17, 392

Brugmans, J., Van Cutsem, J. M., Thienpont, D., Archives of Dermatology, 1970, 102, 428. 3 Godts, P., Vermylen, P., and Van Cutsem, J. M.,

Annals, of the New York Academy of Sciences, 1970, 174, 606.

\section{Pyomyositis in London}

SIR,-I would agree with Dr. P. E. T. Isaac's view (27 October, p. 235) that the interesting case of gluteal abscess described by Dr. D. W. Rogers (29 September, p. 679) falls into a different category from that of tropical pyomyositis. Denial by the patient is no guarantee that there has been no recent injection in this site, the lapse of memory being sometimes genuine and sometimes-for a variety of reasonsfeigned. Tropical pyomyositis, first described by Scott in the West Indies in 1912,1 has been reported with such frequency since then from areas confined to the tropical belt which encircles the world, that it must surely be associated with some common factor (such as parasites) encountered in these areas.

However, I would disagree with Dr. Isaac's assertion that the lesions of tropical pyomyositis are always multiple. Buxton, in his classic monograph on the disease, ${ }^{2}$ did not make this distinction. In a personal series of 65 cases reported from Nigeria ${ }^{34}$ there were 55 single abscesses, while in only 10 cases were three multiple abscesses. In this series nematode larvae in large numbers were demonstrated in the pus from intramuscular abscesses. The following aetiological hypothesis was advanced: (1) From initial nematode infestation (ancylostoma, dracunculus, etc.) shoals of larvae migrating through the systemic circulation break out through capillaries to be deposited in skeletal muscle, causing a local allergic inflammation (tropical myositis) similar to that which occurs in visceral larva migrans or in ascarid pneumonitis. (2) Subsequent autogenous infection of the lesion-for example, by staphylococci-would produce pyomyositis. These abscesses therefore differ from those caused by adult worms (such as Dracunculus medinensis or filaria), which inhabit subcutaneous planes or lymphatics.

Nematode infestations of differing varieties are heavy in all areas in which tropical pyomyositis is endemic. Numerous attempts have been made before and since the above hypothesis was advanced to explain the aetiology of this disease, but no other offers a factor which is common to every area in which tropical poymyositis is endemic.-I am, etc.,

British Military Hospital,

D. D. O'BRIEN

Rinteln,

Scott, H. H.. Fournal of Tropical Medicine and Hygiene, 1912, 15, 97.

uxton, P. G., Researches in Polynesia, Memoir No. 2, London School of Hygiene and Tropical O'Brien, D.

O'Brien, D. D., fournal of
cal Corps, 1963,109, 43 .

O'Brien, D. D., Transactions of the Royal Society
of Tropical Medicine and Hygiene, 1963, 57, 313.

\section{Nicotine Availability as a Factor in} Tobacco Consumption

SIR,-Dr. M. A. H. Russell and others (1 December, p. 512) suggest that a cigarette could be less harmful if it had "a low tar and carbon monoxide yield but a high, rather than low, nicotine yield." The high correlation between the tar and nicotine yields of cigarettes in the current "league table" precludes the likelihood of such a cigarette being obtainable.

However, there do exist cigarettes in which the nicotine availability is potentially high though the tar content remains relatively low. Nicotine is absorbed more readily in the form of a free base, as it exists in an alkaline smoke, than in the form of a stable salt, as it would be in an acid smoke. ${ }^{1}$ English cigarettes, which are made of flue-cured tobacco of high sugar content, give rise to an acid smoke (about $\mathrm{pH} 4$ ). It has been pointed out by Elson and Betts ${ }^{2}$ that "in the smoke of 'reduced tar and nicotine' cigarettes made of high sugar tobacco not only is the nicotine low but its 'pharmacological availability' is also low because of the progressive increase in acidity during smoking. Is there not some danger therefore that the smoker of these cigarettes, in order to achieve his 'nicotine satisfaction' will smoke more, or, what is perhaps more serious, will increase his tendency to inhale?"

In contrast to this the smoke of cigarettes made mainly from air-cured low sugar content tobacco such as those popular in France and other European countries, and of cigars, becomes progressively more alkaline (to $\mathrm{pH}$ 8 or 9) during the course of smoking. Thus "nicotine satisfaction" should be achieved in smoking of fewer cigarettes and with less tendency to inhale. The annual cigarette consumption per head in France over the years 1930 to 1965 averaged about 900 , while in the United Kingdom it was over 2,000. The $d: a \cdot h$ rate from cancer of the lung, bronchus, and trachea in France is less than half that in England and Wales.

The inference would seem to be that for compulsive smokers an indication toward less harmful smcking lies in the direction of decreased tar and nicotine content of the smoke together with a reduced acidity, so that a reasonable degree of "nicotine satisfaction" can be achieved with minimum lung cancer risk from inhalation of carcinogenic" tar. Reduced acidity of the smoke can be achieved by replacing part, at any rate, of the fluecured tobacco by air-cured tobacco of low sugar content or by the synthetic "substitute smoking materials" now being developed, which presumably contain no sugar or nicotine. With the latter however, a sufficient degree of alkalinity of the smoke may not be achieved. A further or additional possibility ${ }^{2}$ is the use of tobacco additives which give rise to an alkaline vapour at the usual temperature of combustion of cigarettes.-I am, etc.,

Epsom Downs, Surrey

L. A. ELSON

1 Elson, L. A., Betts, T. E., and Passey, R. D., 2 Elson, L. A., and Betts, T. E., Fournal of the

\section{Co-trimoxazole Resistance}

SIR,-The occurrence of mutants lacking in thymine (thy) has been recently described ${ }^{12}$ and led Dr. R. W. Lacey and Mrs. Evelyn L. Lewis (20 October, p. 165) to the assumption that significant quantities of thymidine are present in body tissues and that therefore 